\title{
STUDENTS' VIEWS ON THE ROLE OF ETHICS EDUCATION FOR THEIR FUTURE MEDICAL PRACTICE
}

\author{
Nikoleta Leventi ${ }^{1}$, Alexandrina Vodenitcharova ${ }^{2}$, Kristina Popova $^{3}$, Kremena Ivanova $^{4}$, \\ Svetlin Georgiev ${ }^{5}$, Antoniya Yanakieva ${ }^{6}$
}

\begin{abstract}
:
INTRODUCTION: Worldwide, in different ways, ethical dilemmas arise in medicine and life sciences. It is critical for medical professionals to respond with confidence when ethical challenges are addressed in their clinical practice. Medical ethics and bioethics education is recognized as an essential course of the medical curriculum. The course aims to provide students with knowledge and competencies on dealing with moral problems.

OBJECTIVES: In this article, we aim to explore students' views about the importance and role of medical ethics education for their future practice. Their suggestions on specific medical ethics and bioethics topics were also considered, as well as previous knowledge on ethics before they enrolled in university.

METHODS: A paper questionnaire was developed and distributed among first-year foreign medical students from the Faculty of Medicine in the Medical University-Sofia in Bulgaria. All students participated in the study anonymously and voluntarily. The study was conducted during January and February 2020.

RESULTS: Completed questionnaires were received from 366 medical students. Data collected demonstrates that only $19 \%$ of the students were taught ethics before enrolling in university and covered topics on philosophy and ethics, civil and human rights. The majority (92\%) of the responders believe that the study of medical ethics and bioethics helps medical professionals to improve their skills in identifying ethical problems in their everyday practice. Interesting were the suggestions for topics in medical ethics and bioethics that needed further study during lectures and seminars and included principles of medical ethics and bioethics, ethical behavior in medicine and health care, ethical dimensions of new technologies in health care, ethical dimensions of clinical decisions and patients' quality of life, ethics and health management.

CONCLUSIONS: Medical ethics education is significant for future physicians, helping them to improve their skills in identifying ethical issues, and base their decisions on fundamental ethical principals in their everyday practice. Attention should be given to topics related to principles of medical ethics, models of patient-physician relationships, new technologies in health care, ethics and health policy.
\end{abstract}

UDC Classification: 614.2, DOI: https://doi.org/10.12955/pmp.v2.178

Keywords: bioethics, medical ethics education, ethical dilemmas.

\section{Introduction}

The current COVID-19 pandemic shows that ethical challenges in healthcare become more and more difficult, for example, when the allocation of scarce resources is critical for patients. Medical professionals need to be equipped with skills and knowledge to deal effectively in clinical practice, using goals and methods of medical research (Vodenicharova et al., 2015; WHO, 2013).

Medical ethics/bioethics as an academic discipline are incorporated in the curriculum of many medical schools worldwide. The goal of the course is to help students become familiar with the fundamental principles of medical ethics (Beauchamp \& Childress, 2013), as well as to develop an awareness of ethical dilemmas that they will face in their future careers as physicians (Bioethics Core Curriculum, UNESCO, (2016)).

This education also strives to motivate future physicians to analyze ethical dimensions, express their opinion and help them to make value-based decisions by applying ethical principles and theories.

\footnotetext{
${ }^{1}$ Medical University - Sofia, Faculty of Public Health, Department Health Technology Assessment, Sofia, Bulgaria, n.leventi@foz.mu-sofia.bg, ORCID: 0000-0002-5801-980X

${ }^{2}$ Medical University - Sofia, Faculty of Public Health, Department of Bioethics, Sofia, Bulgaria,

a.vodenicharova@foz.mu-sofia.bg

${ }^{3}$ Medical University - Sofia, Faculty of Public Health, Department of Social Medicine, Sofia, Bulgaria, k.popova@foz.mu-sofia.bg

${ }^{4}$ Medical University - Sofia, Faculty of Public Health, Department Health Technology Assessment, Sofia,

Bulgaria,k.ivanova@foz.mu-sofia.bg

${ }^{5}$ Medical University - Sofia, Faculty of Public Health, Department Health Technology Assessment, Sofia, Bulgaria, s.georgiev@foz.mu-sofia.bg

${ }^{6}$ Medical University - Sofia, Faculty of Public Health, Department Health Technology Assessment, Sofia, Bulgaria, a.yanakieva@foz.mu-sofia.bg
} 
The design of our curriculum is innovative and prepares students for when they will apply this knowledge in theory and in real-life cases.

The program uses a theoretical framework (The UNESCO Universal Declaration on Bioethics and Human Rights: Background, Principles and Application, 2009) with lectures and seminars with a case study approach (UNESCO Chair in Bioethics, Casebook on Bioethics for Judges, 2016; UNESCO Chair in Bioethics, Casebook on Human Dignity and Human Rights, 2011). Students are introduced to a case (UNESCO Chair in Bioethics, Informed Consent, 2003), discuss the moral conflicts that arise and their implications on the care of patients.

Teachers of medical ethics/bioethics at our university are members of the Bulgarian Unit of the International Bioethics Network of UNESCO and apply in their teaching practice the methodology of the UNESCO Department on Bioethics.

The aim of this survey is to explore students' views about the importance and role of medical ethics education in their future practice. The students were also asked to suggest specific medical ethics and bioethics topics. Finally, focus is given towards previous knowledge on ethics before their enrollment in university.

\section{Methods}

To achieve the purpose of the survey, a web-based questionnaire was distributed among 366 first-year medical students in the Medical University of Sofia, Faculty of Medicine. The survey was conducted from January to February 2020, and all the students responded anonymously and voluntarily. The web-based questionnaire included in total 10 questions -among them four open-ended questions and 6 closed. The range of the answers to the closed questions was:

- Yes / No

- Yes, No, "cannot evaluate"

- "very important", "important ", "I cannot evaluate", "less important", and "not at all important".

The questions focused on students' previous studies on ethics and special topics that had been taught before they enrolled in university. In addition, we explored what were, according to students' opinion, the most important topics on medical ethics and bioethics and what were the source of information they used during the course. The data was analyzed through a descriptive statistical method.

\section{Results}

Among all students that responded to the questionnaire, 19\% answered positively to the question related to their previous studies of ethics before they enrolled in medical university (Fig. 1).

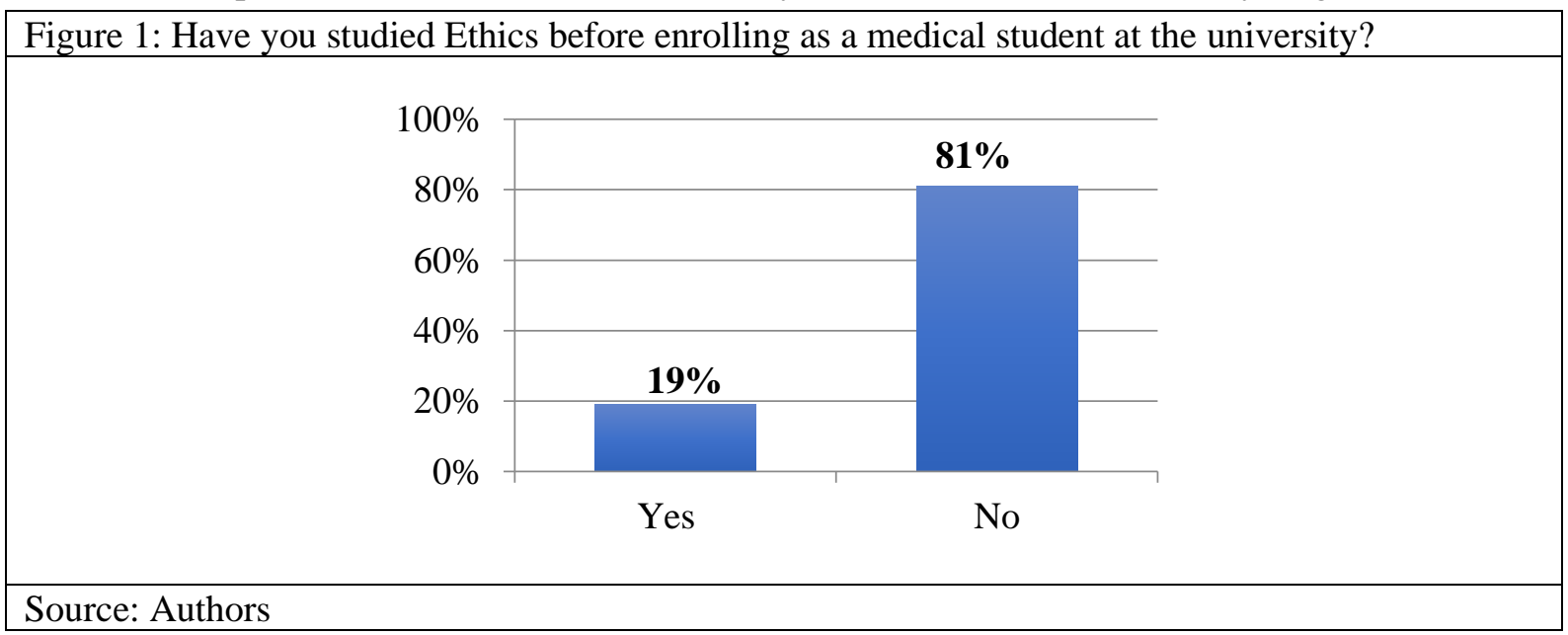

It was interesting to explore the covered topics on ethics for those who studied ethics before enrolling in university, as philosophy and ethics (54\%), civil and human rights topics (17\%), 11\% reported ethics and human trials, and $17 \%$ reported other topics (Fig. 2).

It is worth mentioning that the majority of the participants, $92 \%$, believe that the study of medical ethics/bioethics helps medical professionals to improve their skills in identifying ethical issues in their everyday practice, while $6 \%$ of the students cannot evaluate and only $2 \%$ of them stated "no" (Fig. 3). 


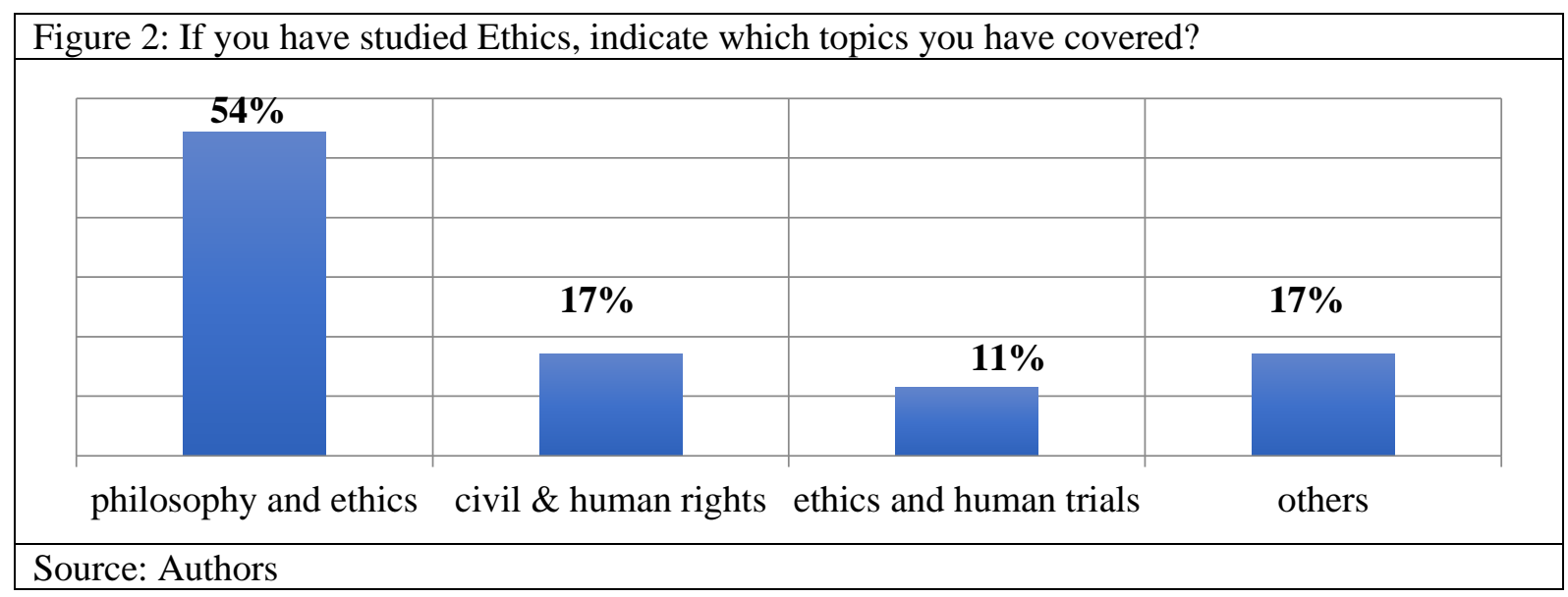

Figure 3: Do you believe that the study of medical Ethics and Bioethics helps medical professionals to improve their skills in identifying ethical problems in their everyday practice?

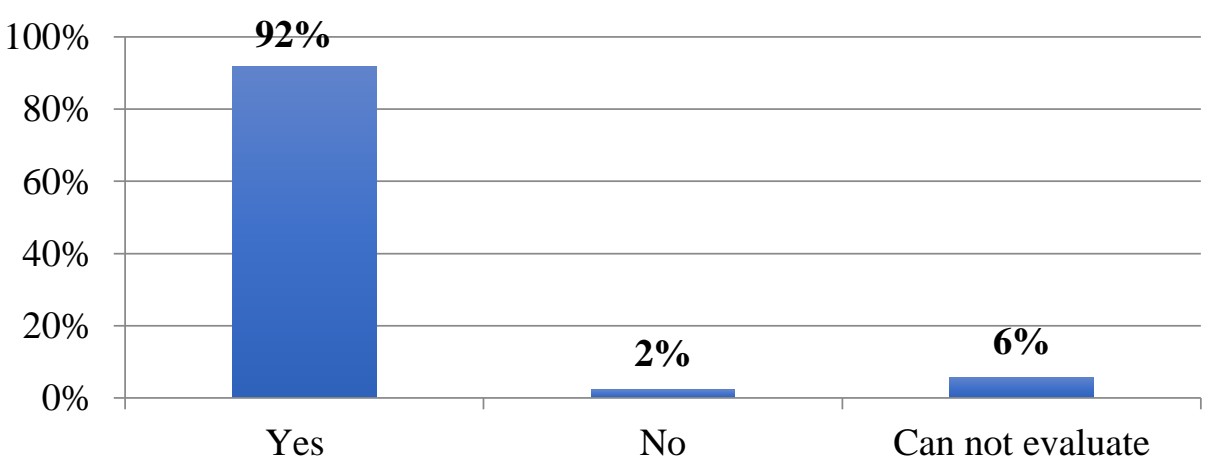

\section{Source: Authors}

The next question was related to the topics of medical ethics/bioethics that we covered in our program and students found useful for their future medical practice. The percentage distribution was as followed, 34\% answered ethical principles, 31\% indicated bioethics topics, $14 \%$ rules for good medical practice, $10 \%$ everything about informed consent, $6 \%$ the relationship between physician and patient, $4 \%$ stated the case studies, and $1 \%$ risk management in healthcare (Fig. 4).

Figure 4: What topics of Medical Ethics at our university do you think are very useful for your future medical practice?

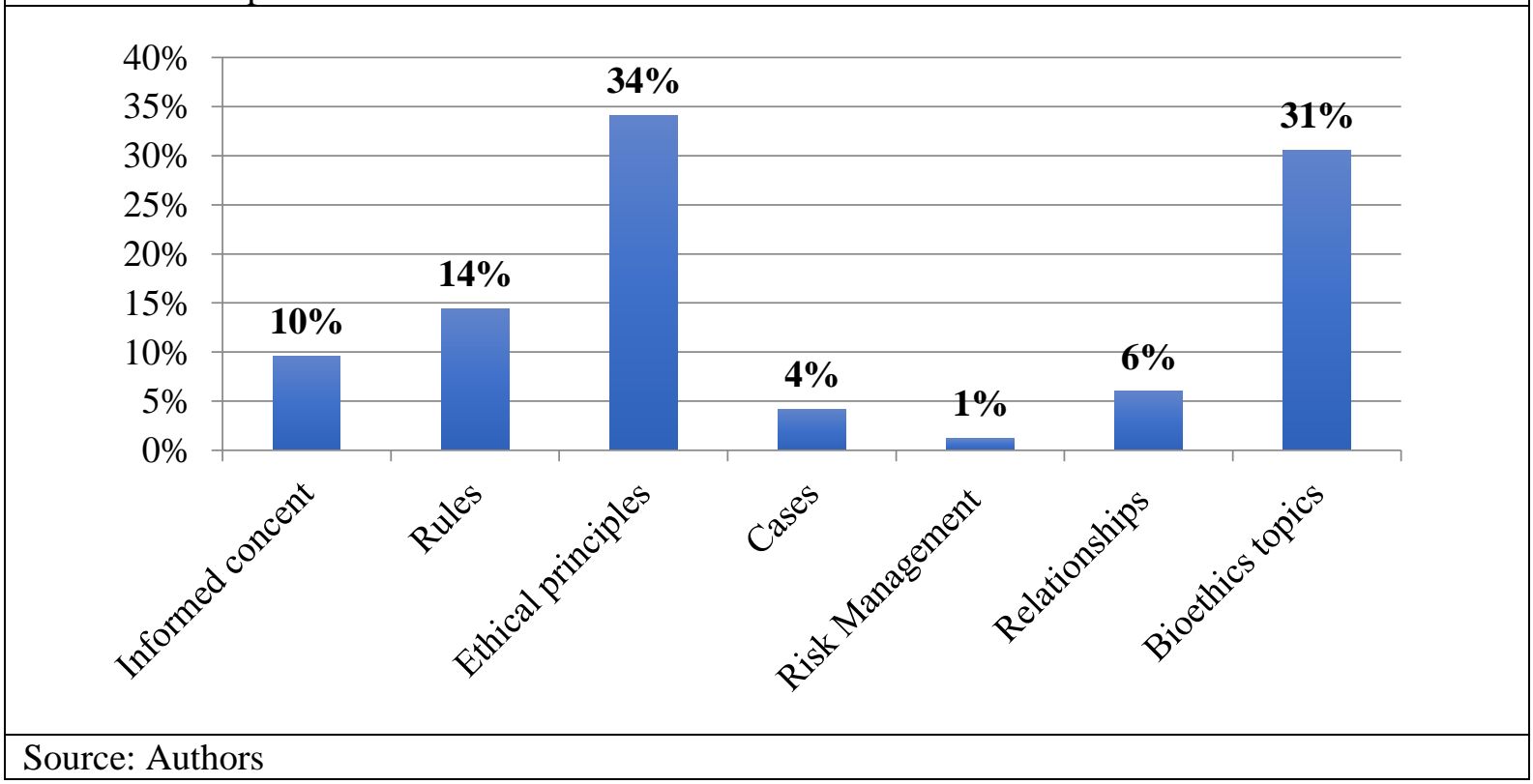


The majority of the participants, $91 \%$, did not have any suggestions for topics in medical ethics that might be needed to be included for further study. The remaining $9 \%$ suggested further study into case studies (38\%), on topics related to rules for good medical practice (31\%), and on informed consent topics (31\%) (Fig. 5).

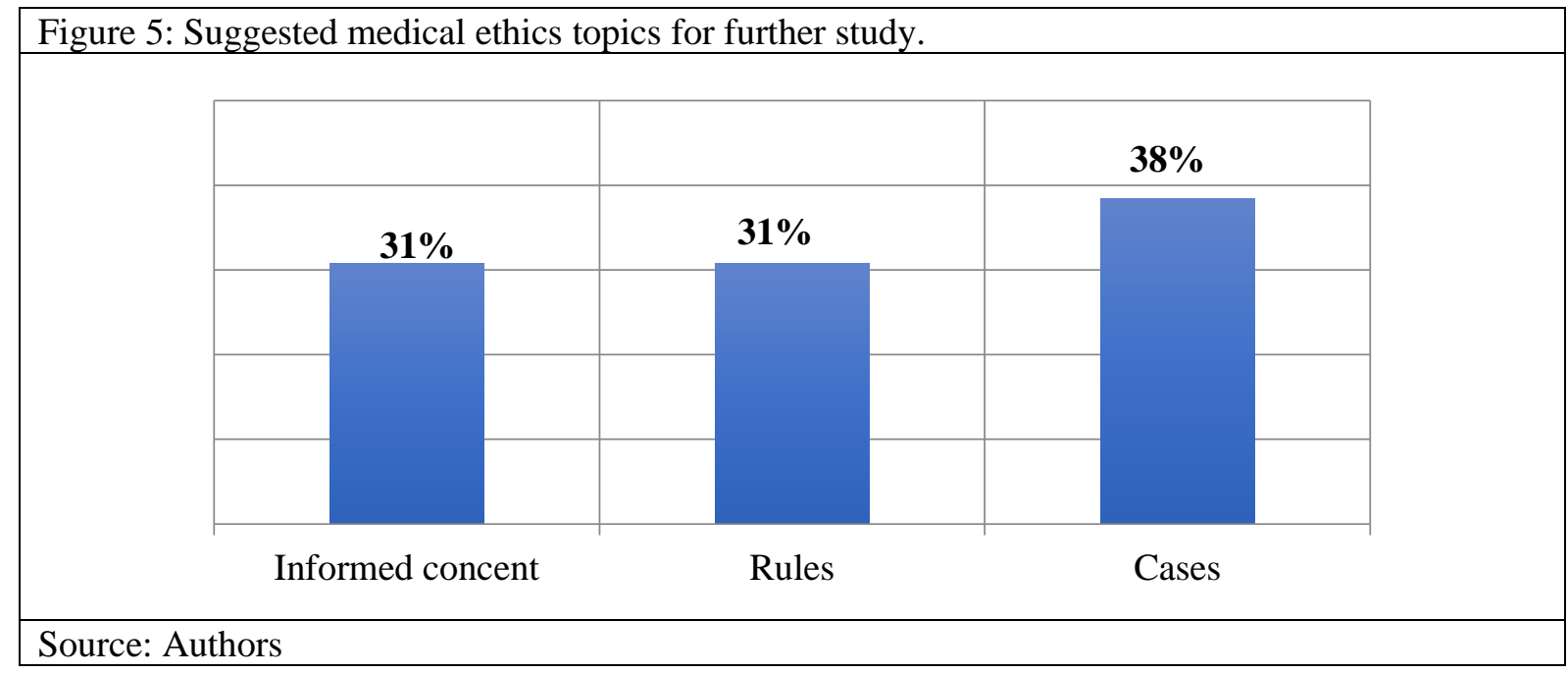

To the question "indicate which topics of bioethics are the most important", participants answered as follows in the next table (Table 1).

\begin{tabular}{|l|c|c|c|c|c|}
\hline \multicolumn{6}{|l|}{ Table 1: Which topics of Bioethics are the most important? } \\
\hline $\begin{array}{c}\text { Indicate which topics of Bioethics } \\
\text { are the most important: }\end{array}$ & $\begin{array}{c}\text { very } \\
\text { important }\end{array}$ & important & $\begin{array}{c}\text { cannot } \\
\text { evaluate }\end{array}$ & $\begin{array}{c}\text { less } \\
\text { important }\end{array}$ & $\begin{array}{c}\text { not } \\
\text { important }\end{array}$ \\
\hline Organ transplantation & $64 \%$ & $32 \%$ & $3 \%$ & $1 \%$ & $0 \%$ \\
\hline Organ donation & $65 \%$ & $29 \%$ & $4 \%$ & $2 \%$ & $0 \%$ \\
\hline Abortion & $60 \%$ & $28 \%$ & $8 \%$ & $2 \%$ & $1 \%$ \\
\hline Euthanasia & $60 \%$ & $22 \%$ & $13 \%$ & $5 \%$ & $1 \%$ \\
\hline Human gene therapy & $49 \%$ & $31 \%$ & $11 \%$ & $5 \%$ & $1 \%$ \\
\hline In Vitro Fertilization & $36 \%$ & $39 \%$ & $12 \%$ & $13 \%$ & $1 \%$ \\
\hline Environmental ethics & $34 \%$ & $34 \%$ & $13 \%$ & $15 \%$ & $1 \%$ \\
\hline Other & $1 \%$ & $0 \%$ & $0 \%$ & $0 \%$ & $0 \%$ \\
\hline Sour &
\end{tabular}

Source: Authors

The last question was regarding the bioethics recourses of information the students used during their studies. From data collected, $48 \%$ of the respondents reported materials from the web page of UNESCO chair in bioethics, 28\% materials from lectures and seminars, $12 \%$ internet resources, $7 \%$ from $\mathrm{WHO}$, and $4 \%$ bioethics books (Fig. 6).

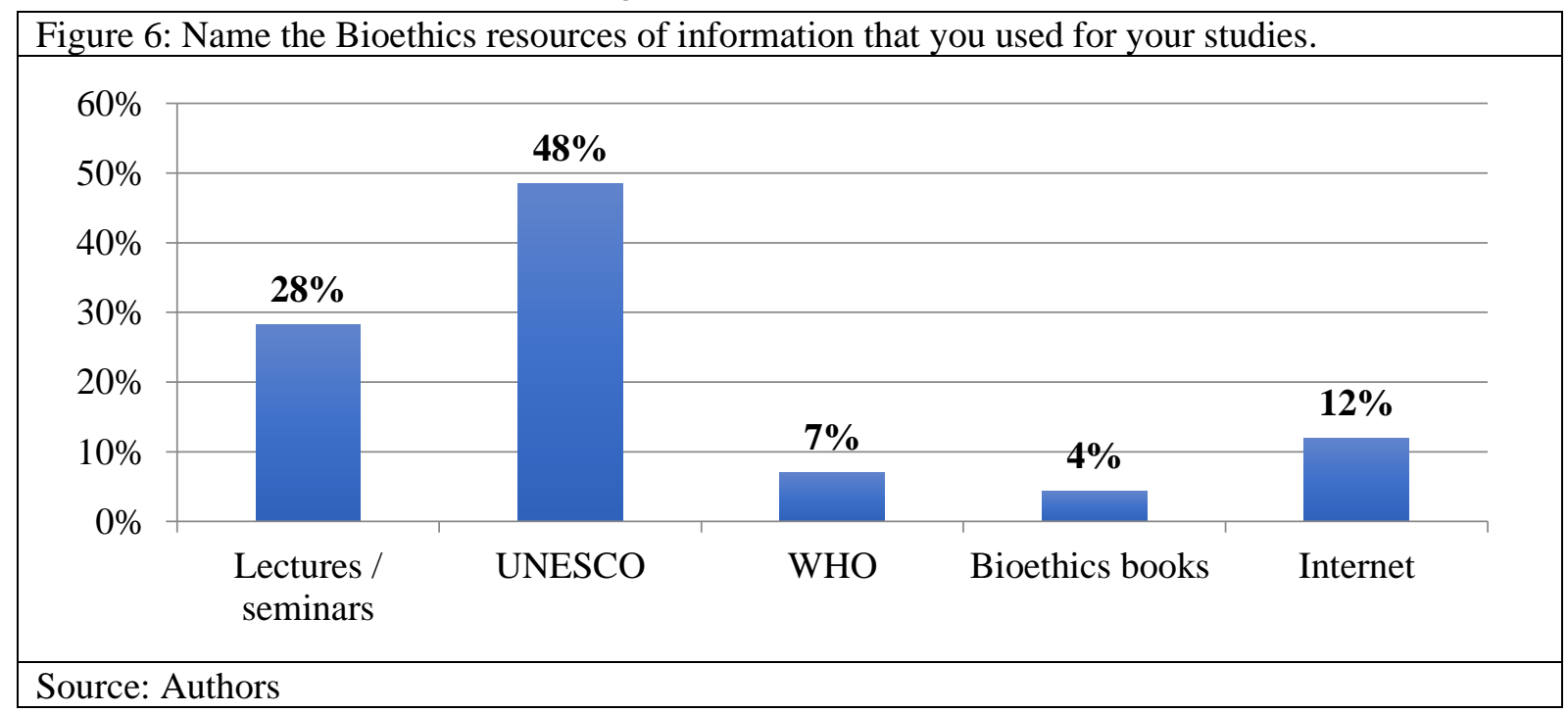




\section{Conclusion}

The article presented students' views about the significance of medical ethics education for the practice of future physicians. Special consideration was given to specific topics on medical ethics / bioethics as well as the previous knowledge on ethics before the students enrolled in university. A prominent source of knowledge during the course were materials from UNESCO followed by lectures/seminars, Internet retrieved sources, and WHO provided materials. Medical ethics education helps future physicians to improve their skills in identifying ethical issues and base their decisions on the fundamental ethical principals in their everyday practice. The outcome of medical ethics education is to provide students with competencies and knowledge on dealing with ethical issues. We received some interesting suggestions about further study on topics related to principles of medical ethics, models of patient-physician relationships, new technologies in health care, ethics and health policy.

\section{References}

Beauchamp T L, Childress J F., 2013, Principles of Biomedical Ethics, 7th Edition, Oxford University Press, ISBN: 978-019-992458-5

Bioethics Core Curriculum, UNESCO, 2016, Ethics Education Programme, Division of Science and Technology, Website: www.unesco.org/shs/ethics/eep, retrieved April 2021

WHO, 2013, Health 2020: A European Policy Framework and Strategy for the 21st Century,

http://apps.who.int/iris/bitstream/10665/131303/1/ Health 2020 Long.pdf, accessed March 2021

The UNESCO Universal Declaration on Bioethics and Human Rights: Background, Principles and Application, 2009, Ethics series. ISBN 978-92-3-104088-7, http://www.unesco-chair-bioethics.org/

UNESCO Chair in Bioethics, Casebook on Bioethics for Judges, 2016, Ethics series. ISBN 978-965-444-037-0, http://www.unesco-chair-bioethics.org/

UNESCO Chair in Bioethics, Casebook on Human Dignity and Human Rights, 2011, Ethics series. ISBN 978-92-3-1042034, http://www.unesco-chair-bioethics.org/

UNESCO Chair in Bioethics, Informed Consent, 2003, Ethics series. ISBN 965-7077-22-2, http://www.unesco-chairbioethics.org/

Vodenicharova Al., Popova K., Yanakieva A., 2015, Leading the Change in Medical Practice: The Role of Bioethics. International Journal of Research in Management and Social Science. Vol.3, Issue 1 (V): January - March 2015, 60-63 pp.

World Report on Ageing and Health. WHO 2015, World Health Organization, 246 p. WHO Library Cataloguing-inPublication Data ISBN 9789240694811 (PDF), WHO website (www.who.int) 